\title{
BAY 58-2667, an NO-independent guanylyl cyclase activator, pharmacologically post-conditions rabbit and rat hearts Thomas Krieg*1, Yanping Liu ${ }^{2}$, Thomas Rütz ${ }^{1}$, Carmen Methner ${ }^{1}$, Xi- Ming Yang ${ }^{2}$, Stephan B Felix ${ }^{1}$ and James M Downey ${ }^{2}$
} \author{
Alabama, Mobile, AL, USA \\ Email: Thomas Krieg* - krieg@uni-greifswald.de \\ * Corresponding author \\ from 4th International Conference of cGMP Generators, Effectors and Therapeutic Implications \\ Regensburg, Germany. 19-2I June 2009 \\ Published: II August 2009 \\ BMC Pharmacology 2009, 9(Suppl I):P36 doi:I0.1186/147I-2210-9-SI-P36
}

Address: ${ }^{1}$ Department of Cardiology, Ernst-Moritz-Arndt University, Greifswald, Germany and ${ }^{2}$ Department of Physiology, University of South

This abstract is available from: http://www.biomedcentral.com//47I-2210/9/SI/P36

(c) 2009 Krieg et al; licensee BioMed Central Ltd.

\section{Background}

BAY 58-2667 (cinaciguat) directly activates soluble guanylyl cyclase without tolerance in a NO-independent manner, and its hemodynamic effect is similar to that of nitroglycerin. We tested whether BAY 58-2667 could make both rabbit and rat hearts resistant to infarction when given at the end of an ischemic insult.

\section{Methods and results}

All hearts were exposed to 30-min regional ischemia followed by 120-(isolated hearts) or 180-(in situ hearts) min reperfusion. BAY 58-2667 (1-50 nM) infused for 60-min starting 5-min before reperfusion significantly reduced infarction from $33.0 \pm 3.2 \%$ in control isolated rabbit hearts to $9.5-12.7 \%(p<0.05)$. In a more clinically relevant in situ rabbit model infarct size was similarly reduced with a loading dose of $53.6 \mu \mathrm{g} / \mathrm{kg}$ followed by a $60-\mathrm{min}$ infusion of $1.25 \mu \mathrm{g} / \mathrm{kg} / \mathrm{min}(41.1 \pm 3.1 \%$ infarction in control hearts to $16.0( \pm) 4.4 \%$ in treated hearts, $\mathrm{p}<0.05)$. BAY 58-2667 similarly decreased infarction in the isolated rat heart, and protection was abolished by co-treatment with a protein kinase $\mathrm{G}$ (PKG) antagonist, or a mitochondrial $\mathrm{K}_{\text {ATP }}$ channel antagonist. Conversely, $\mathrm{N}^{\omega}{ }^{\omega}$-nitro-Larginine-methyl-ester-hydrochloride, a NO-synthase inhibitor, failed to block BAY 58-2667's ability to decrease infarction, consistent with the latter's putative NO-independent activation of PKG. Finally, BAY 58-2667 increased myocardial cGMP content in reperfused hearts while cAMP was unchanged.

\section{Conclusion}

When applied at reperfusion BAY 58-2667 is an effective cardioprotective agent with a mechanism similar to that of ischemic preconditioning and, hence, should be a candidate for treatment of acute myocardial infarction in man. 